\title{
Strong influence of dietary intake and physical activity on body fatness in elderly Japanese men: age-associated loss of polygenic resistance against obesity
}

\author{
Kumpei Tanisawa $\cdot$ Tomoko Ito $\cdot$ Xiaomin Sun $\cdot$ \\ Ryuken Ise - Satomi Oshima $\cdot$ Zhen-Bo Cao • \\ Shizuo Sakamoto $\cdot$ Masashi Tanaka $\cdot$ Mitsuru Higuchi
}

Received: 21 April 2014/Accepted: 23 June 2014/Published online: 17 July 2014

(C) Springer-Verlag Berlin Heidelberg 2014

\begin{abstract}
Genome-wide association studies identified single nucleotide polymorphisms (SNPs) associated with body mass index (BMI) in middle-aged populations; however, it is unclear whether these SNPs are associated with body fatness in elderly people. We examined the association between genetic risk score (GRS) from BMI-associated SNPs and body fatness in elderly Japanese men. We also examined the contribution of GRS, dietary macronutrient intake, and physical activity to body fatness by different age groups. GRS was calculated from 10 BMI-associated SNPs in 84 middle-aged (30-64 years) and 97 elderly (65-79 years) Japanese men; subjects were divided into low, middle, and high GRS groups. Dietary macronutrient intake was assessed using a questionnaire, and physical activity was evaluated using both a questionnaire and an accelerometer. The middle-aged individuals with a high GRS had greater BMI; waist circumference; and total abdominal fat, visceral fat, and subcutaneous fat areas than the middle-aged individuals with
\end{abstract}

\footnotetext{
K. Tanisawa $\cdot$ T. Ito $\cdot X$. Sun $\cdot$ R. Ise

Graduate School of Sport Sciences, Waseda University, 2-579-15 Mikajima, Tokorozawa, Saitama 359-1192, Japan e-mail: kunpei-tanisawa@fuji.waseda.jp

K. Tanisawa $\cdot$ M. Tanaka

Department of Genomics for Longevity and Health,

Tokyo Metropolitan Institute of Gerontology,

35-2 Sakae-cho, Itabashi-ku, Tokyo 173-0015, Japan

S. Oshima - Z.-B. Cao $\cdot$ S. Sakamoto - M. Higuchi $(\bowtie)$

Faculty of Sport Sciences, Waseda University,

2-579-15 Mikajima, Tokorozawa, Saitama 359-1192, Japan

e-mail: mhiguchi@waseda.jp

S. Sakamoto $\cdot$ M. Higuchi

Institute of Advanced Active Aging Research,

Waseda University, 2-579-15 Mikajima, Tokorozawa,

Saitama 359-1192, Japan
}

low GRS, whereas the indicators were not different between the GRS groups in elderly individuals. Multiple linear regression analysis showed that GRS was the strongest predictor of BMI, total abdominal fat, and visceral fat in the middle-aged group, whereas fat, alcohol, and protein intakes or vigorous-intensity physical activity were more strongly associated with these indicators than was GRS in the elderly group. These results suggest that GRS from BMI-associated SNPs is not predictive of body fatness in elderly Japanese men. The stronger contribution of dietary macronutrient intake and physical activity to body fatness may attenuate the genetic predisposition in elderly men.

Keywords Body fatness - Aging - SNP - Genetic risk score $\cdot$ Dietary macronutrient intake $\cdot$ Physical activity

\section{Introduction}

The prevalence of obesity in elderly populations is increasing worldwide, including in Asian countries (Popkin and Doak 1998). Obesity and abdominal adiposity increases the risk of cardiometabolic diseases, sarcopenic obesity, and functional disability even in the elderly Asian individuals who generally have a lower body mass index (BMI) than European people (Kim et al. 2009; Ochi et al. 2010; WHO Expert Consultation 2004). Therefore, identifying the determinants of obesity in elderly Asian individuals is important to prevent obesity and to reduce the burden of health care in a rapidly aging society in Asia.

Genetic variation is an important determinant of susceptibility to obesity. Recent genome-wide association studies (GWASs) identified single nucleotide polymorphisms (SNPs) at several genetic loci that are associated with BMI in European and Asian populations (Thorleifsson et al. 2009; 
Wen et al. 2012; Willer et al. 2009). Several studies calculated the genetic risk score (GRS) from the number of risk alleles of GWAS-derived SNPs to examine the polygenic effect of these variants and demonstrated that the GRS is strongly associated with BMI (Cheung et al. 2010; Peterson et al. 2011; Renstrom et al. 2009). However, most of these BMI-associated SNPs were identified in the cohorts consisting of mainly middle-aged individuals; therefore, it is unclear whether these SNPs and GRS are also associated with BMI and indices of adiposity in elderly people.

Interestingly, a recent study reported that the SNPs previously associated with BMI in middle-aged populations and GRS constructed from these variants were not associated with body weight or body fatness in the older European and African-American populations (Murphy et al. 2013). In that study, Murphy et al. further suggested that an increase in body weight from midlife to old age might underlie the weak associations between SNPs and body fatness. However, in contrast to European and African individuals, Asian people generally maintain their body weight from midlife to later life (Funatogawa et al. 2009). Therefore, BMI-associated SNPs identified in middle-aged populations may be associated with BMI and other indicators of body fatness in the elderly Asian populations.

Moreover, not only genetic factors, but also environmental factors including lifestyle, such as dietary intake and physical activity, are associated with obesity (Donnelly et al. 2009; Mozaffarian et al. 2011); however, Murphy et al. did not examine the association of SNPs with body weight in relation to environmental factors. Twin studies demonstrated that the contribution of genetic factors to body weight might decrease with advancing age (Carmichael and Mcgue 1995; Korkeila et al. 1991). Alternatively, environmental factors may have stronger effects on body weight because the genetic influence lessens when people become older. Therefore, it should be examined whether the contribution of environmental factors to body fatness is different between middle-aged and elderly individuals.

In the present study, we calculated GRS on the basis of BMI-associated SNPs previously identified in middle-aged Asian populations. We examined whether GRS is associated with indicators of body fatness in middle-aged and elderly Japanese men, respectively. We also examined whether the contribution of GRS, dietary macronutrient intake, and physical activity to body fatness differ by age groups.

\section{Materials and Methods}

\section{Subjects}

Eighty-four middle-aged (30-64 years) and 97 elderly (65-79 years) Japanese men participated in this study. All subjects were free from endocrine disorders that might affect their body weight (e.g., Cushing disease, hypothyroidism, hypothyroidism). Subjects also did not take any medications that might affect energy expenditure (e.g., steroids, thyroid hormones). Diabetes status was defined in accordance with World Health Organization criteria (Alberti et al. 1998); 11 subjects $(6.1 \%)$ had type 2 diabetes. Current/former smoking status was assessed with a questionnaire. All subjects provided written informed consent before enrollment in the study, which was approved by the Ethical Committee of Waseda University. The study was conducted in accordance with the Declaration of Helsinki.

\section{Anthropometric characteristics}

Body weight and body fat percentages (assessed by bioelectrical impedance analysis) were measured using an electronic scale (InnerScan BC-600, Tanita Inc., Tokyo, Japan), whereas height was measured with a stadiometer (YL-65, YAGAMI Inc., Nagoya, Japan). BMI was calculated from measurements of body weight and height. Waist circumference was measured at the umbilical region with an inelastic measuring tape. The total abdominal fat, visceral fat, and subcutaneous fat areas were measured using magnetic resonance imaging (Signa 1.5 T, General Electric Inc., Milwaukee, WI, USA). The imaging conditions included a T1-weighted spin-echo and axial-plane sequence with a slice thickness of $10 \mathrm{~mm}$, a repetition time of $140 \mathrm{~ms}$, and an echo time of $12.3 \mathrm{~ms}$ (Usui et al. 2010). Cross-sectional images were scanned at the umbilical region. During the scan, the subjects were asked to hold their breath for approximately $30 \mathrm{~s}$ after inhalation to reduce respiratory motion artifacts. The magnetic resonance images were transferred to a personal computer in the Digital Imaging and Communications in Medicine file format, and the cross-sectional area of the visceral fat at the umbilical region was determined using image-analysis software (sliceOmatic 4.3 for Windows, TomoVision, Montreal, Quebec, Canada). To minimize interobserver variation, the same investigator performed all analyses; the coefficient of variation was $0.4 \%$ for the cross-sectional areas of the umbilical region.

Physical activity

Physical activity was measured using a uniaxial accelerometer (Kenz Lifecorder EX, SUZUKEN Co Ltd., Nagoya, Japan). Instructions for the accelerometer were given to the subjects before the test period; they were told to continuously wear it on their belt or waistband at the right midline of the thigh for 10 days, except when sleeping or bathing. Moderate-intensity physical activity (MPA) and vigorous- 
intensity physical activity (VPA) were used as the indices of physical activity. On a scale with the points $0,0.5$, and 1-9, the Lifecorder system determined the level of physical activity intensity every $4 \mathrm{~s}$. As described previously (Kumahara et al. 2004), the amount of time spent at intensity levels 4-6 and 7-9 were used as the amount of time spent in MPA and VPA, respectively. We also calculated the time spent in moderate- and vigorous-intensity physical activity (MVPA) from MPA and VPA. Subjects recorded leisure time physical activities performed during 10 days in a questionnaire, because several types of activity such as swimming, cycling, and rowing cannot be assessed by an accelerometer. We calculated self-reported time spent in MPA and VPA based on the metabolic equivalents (METs) of each activity (Ainsworth et al. 2000); MPA was defined as 3.0-5.9 METs and VPA as $\geq 6.0$ METs. When an accelerometer indicated intensity levels 0 or 0.5 at the periods that subjects reported as being engaged in MPA or VPA in the questionnaire, we added the time spent in MPA and VPA to the accelerometer-measured MPA and VPA. Total energy expenditure was also assessed through a combination of an accelerometer and a questionnaire such as a MPA and VPA assessment. Valid physical activity data were obtained from 79 (94.0\%) middle-aged and 94 $(96.9 \%)$ elderly subjects and analyzed.

\section{Dietary assessment}

Dietary intake was assessed using a brief self-administered diet history questionnaire (BDHQ). The BDHQ is a 4-page questionnaire that yields information on consumption frequency of selected foods to estimate the dietary intake of 58 food and beverage items (Kobayashi et al. 2011). The validity of the nutrient intake data assessed with the BDHQ was confirmed using semi-weighed 16-day dietary records as a reference (Kobayashi et al. 2012). On the basis of the total daily energy intake and dietary macronutrient intake assessed using the BDHQ, we calculated the percentage of energy intake from carbohydrates, fat, protein, and alcohol.

\section{Collection and analysis of blood samples}

Blood samples were collected between 8:30 and 11:00 a.m. after a 12-h overnight fast and then centrifuged at $3,000 \times g$ for $15 \mathrm{~min}$ at $4{ }^{\circ} \mathrm{C}$. Serum and plasma were stored at $-80{ }^{\circ} \mathrm{C}$ until the time of analysis. Concentrations of HDL cholesterol, LDL cholesterol, triglycerides, and fasting glucose were determined using standard enzymatic techniques (BML, Inc., Tokyo, Japan). Glycated hemoglobin (HbA1c) levels were determined using the latex coagulation method (BML, Inc.).
SNP selection

Ten BMI-associated SNPs were selected for this study. All selected SNPs met the following criteria: (1) a significant genome-wide association $\left(p<5.0 \times 10^{-8}\right)$ in any GWAS of European-descent populations (Thorleifsson et al. 2009; Willer et al. 2009), (2) a suggestive association $\left(p<1.0 \times 10^{-4}\right)$ in the meta-analysis in Asian populations (Wen et al. 2012), and (3) the minor allele frequency (MAF) in the Japanese population was $\geq 0.05$. SEC16B rs574367, TMEM18 rs11127485, TFAP2B rs4715210, and $M C 4 R$ rs6567160 were not included in the SNP array in the present study; these were replaced with rs543874, rs2867125, rs987237, and rs10871777, all of which are in strong linkage disequilibrium with the original SNPs, respectively $\left(\mathrm{D}^{\prime}=1.0, r^{2}>0.7\right.$, in HapMap JPN). All of the SNPs were in Hardy-Weinberg equilibrium $(p>0.001)$ and their MAF was $\geq 0.05$ in our study population (Table 1).

\section{SNP genotyping}

Nuclear DNA was extracted from peripheral blood using the QIAamp DNA Mini kit (QIAGEN, Hilden, Germany); DNA quality was evaluated using agarose gel electrophoresis and spectrophotometry. We confirmed that none of the DNA samples was fragmented and that the A260/A280 ratio was 1.8-2.0. SNP genotyping was performed by using the Infinium HumanExome BeadChip version 1.1 (Illumina, Inc., San Diego, CA, USA) according to the manufacturer's protocol. Genotype calling was performed using the GenTrain clustering algorithm (version 1.0) in the GenomeStudio (ver. 2011.1; Illumina, Inc.). Cluster boundaries were determined using the standard cluster files provided by Illumina. The SNP call rate was at least $98.7 \%$ for all samples.

\section{Calculation of GRS}

We calculated GRS according to the 10 selected SNPs. We assumed that each SNP acts in an additive manner, and the GRS was calculated using a weighted method (Cheung et al. 2010; Renstrom et al. 2009; Tanisawa et al. 2014). Each SNP was weighted by its effect size per allele on BMI (in percentage of the SD) derived from a meta-analysis in Asian populations (Wen et al. 2012). The weighted scores for each SNP were calculated by multiplying each effect size by the number of corresponding risk alleles. These scores were totaled to obtain a GRS for each subject. We divided subjects into the low, middle, and high GRS groups according to the tertile of a GRS. The range for each GRS group was as follows: low: 10-30; middle: $31-38$; and high: 39-67. 
Table 1 SNPs selected to calculate GRS

GRS genetic risk score, $H W E$ Hardy-Weinberg equilibrium, $M$ major allele, $m$ minor allele, $M A F$ minor allele frequency, SNP single nucleotide polymorphism

* Effect of SNPs per allele on BMI (in percentage of the SD) derived from the meta-analysis (Wen et al. 2012)

\begin{tabular}{lllllllll}
\hline SNP & $\begin{array}{l}\text { Gene } \\
\text { symbol }\end{array}$ & Chromosome & $\begin{array}{l}\text { Base pair position } \\
(\text { GRCh37.p10) }\end{array}$ & $\begin{array}{l}\text { Allele } \\
(\mathrm{M} / \mathrm{m})\end{array}$ & $\begin{array}{l}\text { Risk } \\
\text { allele }\end{array}$ & MAF & $\beta^{*}$ & $\begin{array}{l}\text { HWE } \\
p\end{array}$ \\
\hline rs543874 & SEC16B & 1 & 177889480 & $\mathrm{~A} / \mathrm{G}$ & $\mathrm{G}$ & 0.22 & 6.57 & 0.662 \\
rs2867125 & TMEM18 & 2 & 622827 & $\mathrm{C} / \mathrm{T}$ & $\mathrm{C}$ & 0.08 & 5.05 & 0.614 \\
rs713586 & ADCY3 & 2 & 25158008 & $\mathrm{~T} / \mathrm{C}$ & $\mathrm{C}$ & 0.46 & 2.94 & 0.457 \\
rs10938397 & GNPDA2 & 4 & 45182527 & $\mathrm{~A} / \mathrm{G}$ & $\mathrm{G}$ & 0.33 & 3.71 & 0.091 \\
rs987237 & TFAP2B & 6 & 50803050 & $\mathrm{~A} / \mathrm{G}$ & $\mathrm{G}$ & 0.25 & 3.84 & 0.847 \\
rs6265 & BDNF & 11 & 27679916 & $\mathrm{~T} / \mathrm{C}$ & $\mathrm{C}$ & 0.40 & 4.53 & 0.537 \\
rs2241423 & MAP2K5 & 15 & 68086838 & $\mathrm{~A} / \mathrm{G}$ & $\mathrm{G}$ & 0.33 & 3.10 & 1.000 \\
rs17817449 & FTO & 16 & 53813367 & $\mathrm{~T} / \mathrm{G}$ & $\mathrm{G}$ & 0.19 & 8.46 & 0.144 \\
rs10871777 & MC4R & 18 & 57851763 & $\mathrm{~A} / \mathrm{G}$ & $\mathrm{G}$ & 0.24 & 5.64 & 0.223 \\
rs3810291 & TMEM160 & 19 & 47569003 & $\mathrm{~A} / \mathrm{G}$ & $\mathrm{A}$ & 0.23 & 3.48 & 0.003 \\
\hline
\end{tabular}

\section{Statistical analysis}

All statistical analyses were performed with SPSS, version 21.0 (SPSS, Inc., Chicago, IL, USA), or PLINK, version 1.07 (Massachusetts General Hospital, Boston, MA, USA). The allelic frequencies of the selected SNPs were calculated using a gene-counting method, and the HardyWeinberg equilibrium and linkage disequilibrium for each SNP were assessed by the Chi-square test. Student's $t$ test (for normally distributed variables), Mann-Whitney $U$ test (for non-normally distributed variables), or the Chi-square test (for categorical variables) was used to evaluate the differences between the middle-aged and elderly groups. The differences in the indicators of body fatness among age groups and GRS groups were assessed by two-way analysis of covariance (ANCOVA) adjusted for age, current/former smoking status, and type 2 diabetes. A post hoc test with Bonferroni correction was used to identify significant differences among mean values if a significant main effect or interaction was identified. Multiple linear regression analysis was performed to examine the associations of GRS, dietary macronutrient intake, and physical activity with indicators of body fatness in the middle-aged and elderly groups, respectively. All measurements and calculated values are presented as mean $\pm \mathrm{SD}$ (for normally distributed variables) or medians (interquartile range) (for nonnormally distributed variables). The level of significance was set at $p<0.05$.

\section{Results}

\section{Subject characteristics}

The characteristics of the study subjects are shown in Table 2. Height, body weight, and total energy expenditure were lower in the elderly group than in the middle-aged group $(p<0.05)$. Fasting glucose and HbAlc levels were higher in the elderly group than in the middle-aged group $(p<0.05)$.

Association among age groups, GRS groups, and indicators of body fatness

We compared the indicators of body fatness among different age groups and GRS groups. Two-way ANCOVA adjusted for age, current/former smoking status, and type 2 diabetes detected a significant interaction effect between age groups and GRS groups on body weight, BMI, waist circumference, total abdominal fat, visceral fat, and subcutaneous fat. BMI and waist circumference were significantly higher in the high and middle GRS groups than in the low GRS group only among the middle-aged group (Fig. 1a; Table 3, $p<0.05$ ), whereas no significant difference was observed in BMI and waist circumference among different GRS groups in the elderly group. Furthermore, the middle-aged individuals with a high GRS had higher body weight, total abdominal fat, visceral fat, and subcutaneous fat than middle-aged individuals with a low GRS (Fig. 1b; Table 3, $p<0.05$ ); however, these values were not different between the GRS group in the elderly group.

Contribution of GRS, physical activity, and dietary macronutrient intake to body fatness in middle-aged and elderly men

Because the relationship of GRS groups with indicators of body fatness differed by age groups, we performed multiple linear regression analysis to examine the strength of contributions of GRS, physical activity, and dietary macronutrient intake to body fatness in the middle-aged and elderly groups (Table 4). We selected GRS, VPA, fat intake, protein intake, and alcohol intake as independent variables, and BMI, total abdominal fat, and visceral fat as dependent variables. When we entered carbohydrate 
Table 2 Characteristics of the subjects $(n=181)$
Data are mean $\pm \mathrm{SD}$ or median (interquartile range) values. Data were analyzed using Student's $t$ test (for normally distributed variables), MannWhitney $U$ test (for nonnormally distributed variables), or Chi-square test (for categorical variables)

$B M I$ body mass index, $H b A l c$ glycated hemoglobin, $M P A$ moderate-intensity physical activity, MVPA moderate- and vigorous-intensity physical activity, $V P A$ vigorous-intensity physical activity

Boldface indicates significance $(p<0.05)$

* Middle-aged vs. elderly

$\dagger$ Middle-aged: $n=79$; elderly: $n=94$

\begin{tabular}{|c|c|c|c|}
\hline & Middle-aged & Elderly & $p^{*}$ \\
\hline$n$ & 84 & 97 & \\
\hline Age (year) & $53.4 \pm 11.4$ & $70.0 \pm 3.9$ & $<0.001$ \\
\hline Height $(\mathrm{cm})$ & $171.1 \pm 5.8$ & $168.5 \pm 7.1$ & $\mathbf{0 . 0 0 7}$ \\
\hline Body weight (kg) & $70.2 \pm 9.5$ & $66.7 \pm 9.0$ & 0.012 \\
\hline BMI $\left(\mathrm{kg} / \mathrm{m}^{2}\right)$ & $23.9 \pm 2.7$ & $23.4 \pm 2.3$ & 0.172 \\
\hline Body fat (\%) & $20.0 \pm 4.8$ & $21.0 \pm 4.3$ & 0.145 \\
\hline Waist circumference $(\mathrm{cm})$ & $84.0 \pm 8.2$ & $85.1 \pm 6.7$ & 0.325 \\
\hline Total abdominal fat $\left(\mathrm{cm}^{2}\right)$ & $223.2 \pm 93.0$ & $230.0 \pm 73.6$ & 0.592 \\
\hline Visceral fat $\left(\mathrm{cm}^{2}\right)$ & $106.0 \pm 49.4$ & $116.9 \pm 47.6$ & 0.131 \\
\hline Subcutaneous fat $\left(\mathrm{cm}^{2}\right)$ & $117.2 \pm 54.6$ & $113.1 \pm 39.5$ & 0.561 \\
\hline HDL cholesterol (mg/dL) & $57.0(50.0-68.0)$ & $61.0(51.3-68.0)$ & 0.376 \\
\hline LDL cholesterol (mg/dL) & $121.5 \pm 30$ & $122.7 \pm 28.3$ & 0.784 \\
\hline Triglycerides (mg/dL) & $95.0(67.0-127.0)$ & $83.5(65.0-116.0)$ & 0.253 \\
\hline Fasting glucose $(\mathrm{mg} / \mathrm{dL})$ & $95.0(88.0-101.0)$ & $98.0(93.0-105.0)$ & 0.002 \\
\hline $\mathrm{HbA} 1 \mathrm{c}(\%)$ & $4.9(4.8-5.0)$ & $4.9(5.0-5.2)$ & 0.006 \\
\hline Total energy expenditure $(\mathrm{kcal} / \text { day })^{\dagger}$ & $2342 \pm 244$ & $2121 \pm 263$ & $<0.001$ \\
\hline MPA $(\min / \text { day })^{\dagger}$ & $40.0(27.0-55.0)$ & $41.0(21.5-55.0)$ & 0.786 \\
\hline $\operatorname{VPA}(\min / \text { day })^{\dagger}$ & $6.0(1.0-13.0)$ & $2.0(0.0-11.0)$ & 0.081 \\
\hline MVPA $(\min / \text { day })^{\dagger}$ & $51.0(34.0-68.0)$ & $50.5(27.8-68.3)$ & 0.778 \\
\hline Total energy intake (kcal/day) & $2150 \pm 653$ & $2213 \pm 627$ & 0.509 \\
\hline Carbohydrate intake (\% energy) & $51.0 \pm 7.7$ & $50.9 \pm 8.4$ & 0.870 \\
\hline Fat intake (\% energy) & $25.6 \pm 5.1$ & $24.6 \pm 5.6$ & 0.204 \\
\hline Protein intake (\% energy) & $15.1 \pm 2.7$ & $15.0 \pm 2.6$ & 0.956 \\
\hline Alcohol intake (\% energy) & $5.7(2.3-13.7)$ & $7.8(2.4-13.4)$ & 0.583 \\
\hline Current/former smoking status (\%) & 42.9 & 51.5 & 0.243 \\
\hline Type 2 diabetes $(\%)$ & 2.4 & 9.3 & 0.053 \\
\hline
\end{tabular}

intake, fat intake, and alcohol intake into the models simultaneously, the variance inflation factors exceeded 10; therefore, we excluded carbohydrate intake from the models. In the middle-aged group, GRS was the strongest predictor of BMI $(p<0.001)$, total abdominal fat $(p=0.001)$, and visceral fat $(p=0.003)$. On the other hand, other dietary macronutrient intake and VPA were not associated with any indicators of body fatness, although alcohol intake was associated with visceral fat $(p=0.024)$. In contrast to the middle-aged group, high fat intake was the strongest predictor of increased BMI $(p=0.037)$, total abdominal fat $(p=0.001)$, and visceral fat $(p<0.001)$ in the elderly group; however, GRS was not associated with any indicators. Additionally, both low VPA and high alcohol intake were associated with increased total abdominal fat and visceral fat ( $p<0.05$, respectively); low protein intake was also associated with increased visceral fat $(p=0.037)$. We also entered MVPA into the models instead of VPA; however, MVPA was not associated with indicators of body fatness in either the middle-aged or the elderly group.

\section{Discussion}

The main finding of the present study is that GRS from BMI-associated SNPs previously identified in the middleaged populations is not associated with any indicator of body fatness in elderly Japanese men, even though it is a strong predictor of body fatness in middle-aged Japanese men. We also demonstrated that the strength of the contributions of dietary macronutrient intake and physical activity to body fatness differed by the age group, which may explain in part the dissociation of the genetic influence on body fatness in the elderly individuals.

In accordance with our finding, a study recently reported that the SNPs previously associated with BMI in the middle-aged populations were not associated with body weight and adiposity in older European and AfricanAmerican populations (Murphy et al. 2013). In the subjects participating in the longitudinal study, an average weight gain from midlife to old age was about $5 \%$, and only onethird of the subjects maintained body weight within $5 \%$ (Murphy et al. 2013). It was also reported that age-related 

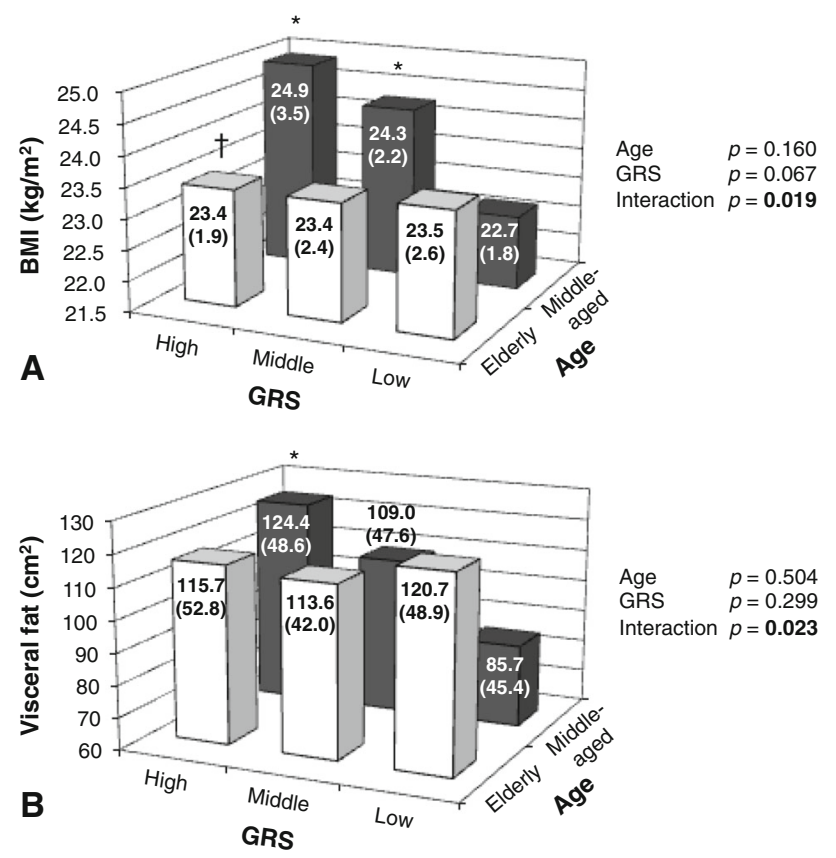

Fig. 1 BMI (a) and Visceral fat (b) among age groups and GRS groups. Data are presented as mean (SD) values. Data were analyzed using two-way ANCOVA adjusted for age, current/former smoking status, and type 2 diabetes. ${ }^{*} p<0.05$ versus the low GRS group within the same age group. $\dagger p<0.05$ versus the middle-aged group within the same GRS group. Boldface indicates significance $(p<0.05)$. BMI body mass index, GRS genetic risk score

body composition and fat distribution changes occur even in weight-stable elderly individuals (Zamboni et al. 2003). These age-related anthropometric changes were suggested to account for the dissociation between BMI-associated SNPs with adiposity in elderly individuals. However, the indicators of body fatness including BMI, body fat percentage, waist circumference, total abdominal fat, visceral fat, and subcutaneous fat were not statistically different between the middle-aged and elderly Japanese individuals in the present study. This suggests that null associations of BMI-associated SNPs with indicators of body fatness may not be explained by changes in body weight and body composition from midlife to old age and are likely common phenomena among various ethnic populations.

Our data have demonstrated that dietary macronutrient intake and physical activity are more strongly associated with body fatness in the elderly than in the middle-aged, suggesting that the relative contributions of genetic and environmental factors to body fatness differ by age groups. Among the dietary factors, fat intake was the most robustly associated with BMI, total abdominal fat, and visceral fat in elderly individuals. Many studies reported that the percentage of energy intake from fat is strongly associated with obesity in Western countries (Bray and Popkin 1998; Dreon et al. 1988). In contrast, no relationship between fat intake and BMI was observed in young Japanese women or

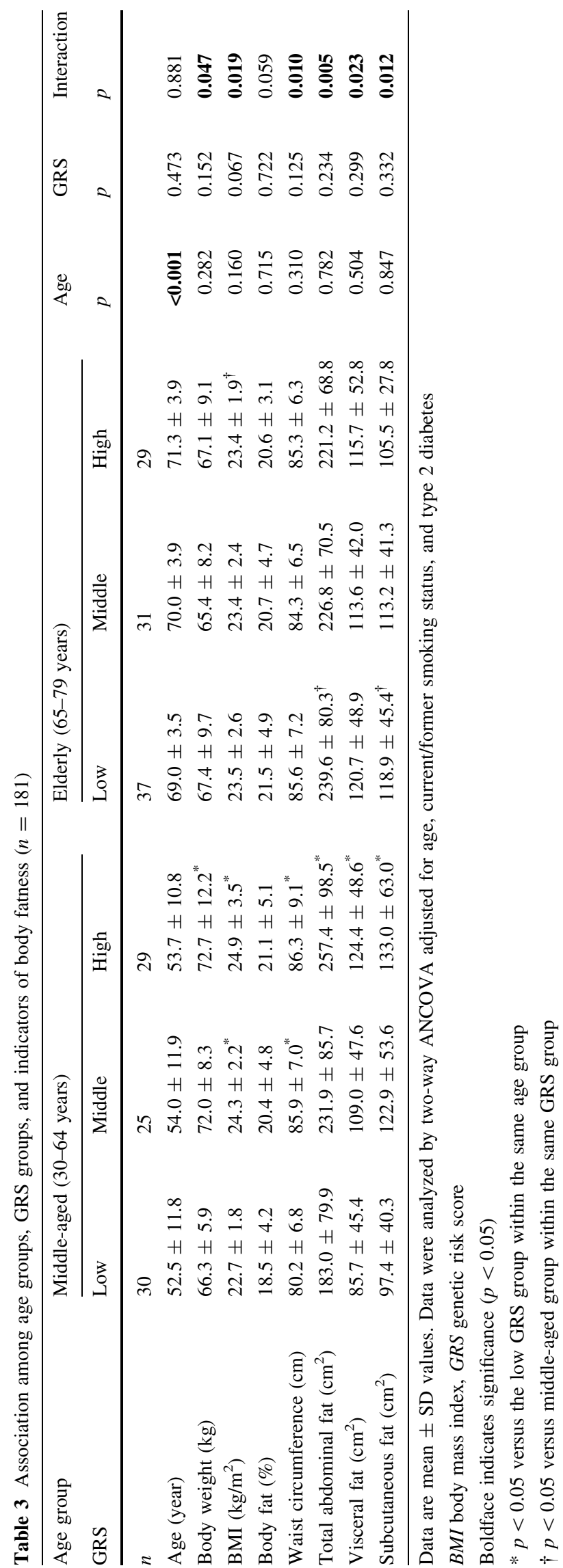


Table 4 Multiple linear regression analysis with BMI, total abdominal fat, and visceral fat as dependent variables $(n=173)$

All models were adjusted for age, current/former smoking status and type 2 diabetes

Boldface indicates significance $(p<0.05)$

$\beta$ standardized coefficient, $B M I$ body mass index, GRS genetic risk score, $V P A$ vigorousintensity physical activity

\begin{tabular}{|c|c|c|c|c|c|c|}
\hline & \multicolumn{2}{|l|}{ BMI } & \multicolumn{2}{|c|}{ Total abdominal fat } & \multicolumn{2}{|c|}{ Visceral fat } \\
\hline & $\beta$ & $p$ & $\beta$ & $p$ & $\beta$ & $p$ \\
\hline \multicolumn{7}{|l|}{ Middle-aged $(n=79)$} \\
\hline GRS & 0.491 & $<0.001$ & 0.382 & 0.001 & 0.321 & 0.003 \\
\hline VPA (min/day) & 0.003 & 0.973 & -0.048 & 0.653 & -0.061 & 0.554 \\
\hline Fat intake (\% energy) & 0.119 & 0.341 & 0.152 & 0.245 & 0.107 & 0.399 \\
\hline Protein intake (\% energy) & 0.180 & 0.130 & 0.174 & 0.160 & 0.176 & 0.144 \\
\hline Alcohol intake (\% energy) & 0.084 & 0.455 & 0.115 & 0.328 & 0.262 & 0.024 \\
\hline Model $r^{2}$ & 0.301 & 0.001 & 0.235 & 0.008 & 0.276 & 0.001 \\
\hline \multicolumn{7}{|l|}{ Elderly $(n=94)$} \\
\hline GRS & 0.035 & 0.752 & -0.049 & 0.633 & 0.004 & 0.968 \\
\hline VPA (min/day) & -0.166 & 0.124 & -0.232 & 0.024 & -0.198 & 0.046 \\
\hline Fat intake (\% energy) & 0.303 & $\mathbf{0 . 0 3 7}$ & 0.460 & 0.001 & 0.520 & $<0.001$ \\
\hline Protein intake ( $\%$ energy) & -0.103 & 0.457 & -0.243 & 0.063 & -0.267 & $\mathbf{0 . 0 3 7}$ \\
\hline Alcohol intake (\% energy) & 0.103 & 0.404 & 0.231 & 0.048 & 0.399 & 0.001 \\
\hline Model $r^{2}$ & 0.082 & 0.453 & 0.187 & 0.016 & 0.231 & 0.002 \\
\hline
\end{tabular}

young and middle-aged Chinese populations in which fat intake was relatively low (mean 29.4 and $24.8 \%$, respectively) (Sasaki et al. 2003; Stookey 2001). Although several lines of evidence is available regarding the effect of fat intake on body fatness in elderly people, reduced fat oxidation is suggested to explain susceptibility to fat accumulation in this group (Levadoux et al. 2001; Rising et al. 1996). This age-related change in energy metabolism may contribute to the strong association between fat intake and body fatness only in elderly individuals despite a relatively low percentage of energy intake from fat. Moreover, high protein intake was also associated with low visceral fat only in elderly individuals. Several studies demonstrated that adequate protein intake prevents age-related muscle loss (Genaro and Martini 2010; Houston et al. 2008). Decline in muscle mass is closely related to visceral adiposity in elderly people (Song et al. 2004; Yamada et al. 2014), which may explain the relationship between high protein intake and low visceral fat in the present study.

Furthermore, a high level of VPA was associated with low total abdominal fat and visceral fat in elderly individuals. Total energy expenditure of physical activity seems to be important for body weight control; however, the benefit of VPA independent from the total volume of activity was documented in several studies. For example, it was demonstrated that high-intensity exercise training induced a greater decrease in subcutaneous skinfolds than low-intensity exercise training, even though traininginduced energy expenditure was about half that in lowintensity exercise training (Tremblay et al. 1994). Highintensity exercise is associated with increased energy expenditure and fat oxidation at a resting state (Treuth et al. 1995, 1996); therefore, VPA may strongly influence body fatness, especially in elderly people with a decreased metabolic rate.

Nevertheless, the total coefficient of determination (model $r^{2}$ ) for BMI was not significant in the elderly, even though model $r^{2}$ for total abdominal fat and visceral fat was comparable between the middle-aged and elderly groups. It suggests that dissociation between GRS and BMI cannot be explained by dietary macronutrient intake and physical activity only. Although BMI is widely used as an indicator of body fatness, it is also associated with total muscle mass in older people (Iannuzzi-Sucich et al. 2002; Kanehisa and Fukunaga 2013). Therefore, genetic factors associated with muscle mass may greatly contribute to individual variations in BMI in the elderly. We should also consider environmental factors in early life. The elderly individuals participating in the present study were born around World War II when Japan faced serious food shortage. Fetal and early childhood malnutrition has been shown to increase the risk of obesity in adulthood (Black et al. 2013; Oken and Gillman 2003); therefore, nutritional status in early life may diminish the association of BMI-associated SNPs with BMI in the elderly Japanese.

The present study has several limitations. First, the sample size was relatively small, which might have led to a type 2 error. Second, although current body weight is influenced by dietary intake and physical activity during the several preceding months, we cross-sectionally examined the association of these values. Prospective studies will provide the more accurate relationship of genetic factors, dietary macronutrient intake, and physical activity with body fatness in elderly individuals. Third, our study included only male subjects. Several twin studies reported that the heritability of BMI differs by sex to a certain 
degree (Korkeila et al. 1991). Last, the majority of the participants in this study were in the normal BMI range (73.5\% of the subjects with a BMI $<25$ ). Our findings should be confirmed by studies with a larger population and a wide range of BMIs and indices of adiposity. In the future, prospective studies will conclude whether aging alters the relationship between GRS from BMI-associated SNPs and body fatness independently of the cohort effect. If the genetic effect gradually decreases throughout life, it is worth examining whether GRS more strongly predicts obesity in a younger population. In addition, identifying the underlying molecular mechanisms, such as by analyzing an age-related change in the epigenetic profiles in BMI-associated genes, will make our findings more persuasive.

In conclusion, the present study revealed that GRS from BMI-associated SNPs previously identified in middle-aged populations is not associated with body fatness in elderly Japanese men. The strong contribution of dietary macronutrient intake and physical activity to body fatness may attenuate the genetic predisposition to obesity in elderly individuals. Our findings suggest that balanced dietary intake and increased physical activity can reduce the risk of obesity in later life, even in individuals with high genetic susceptibility to obesity in midlife. Alternatively, genetic resistance to obesity is lost in an age-dependent manner; therefore, genetically lean middle-aged individuals should sustain a healthy lifestyle to maintain a proper body weight in later life.

Acknowledgments The authors would like to thank Hiroshi Kawano, Yuko Gando, Ryoko Kawakami, Takafumi Ando, Taishi Susa, and Yuko Kobayashi for their assistance. This study was supported in part by a Grant-in-Aid for the Global COE (Sport Sciences for the Promotion of Active Life to Waseda University) (to MT and MH), Grants-in-Aid for Scientific Research (A-22240072, A-25242062, B-21390459, C-21590411 and C-26461480 to M.T.), and a Grant-inAid for Challenging Exploratory Research (26670481 to M.T.) from the Ministry of Education, Culture, Sports, Science, and Technology; by Grants-in-Aid for Research on Intractable Diseases (Mitochondrial Disorders) from the Ministry of Health, Labor, and Welfare of Japan (23-016, 23-116 and 24-005 to M.T.); by grants for scientific research from the Takeda Science Foundation (to M.T.); and by a grant for strategic research initiatives (Paradigm shifts in a super-aged society) from Waseda University (to MH).

Conflict of interest The authors do not have any conflicts of interest to disclose.

\section{References}

Ainsworth BE, Haskell WL, Whitt MC, Irwin ML, Swartz AM, Strath SJ, O'Brien WL, Bassett DR, Schmitz KH, Emplaincourt PO, Jacobs DR, Leon AS (2000) Compendium of physical activities: an update of activity codes and MET intensities. Med Sci Sports Exerc 32(9):S498-S516

Alberti KGMM, Zimmet PZ, Consultation W (1998) Definition, diagnosis and classification of diabetes mellitus and its complications part 1: diagnosis and classification of diabetes mellitus-Provisional report of a WHO consultation. Diabet Med 15(7):539-553

Black RE, Victora CG, Walker SP, Bhutta ZA, Christian P, de Onis M, Ezzati M, Grantham-McGregor S, Katz J, Martorell R, Uauy R, Grp MCNS (2013) Maternal and child undernutrition and overweight in low-income and middle-income countries. Lancet 382(9890):427-451

Bray GA, Popkin BM (1998) Dietary fat intake does affect obesity! Am J Clin Nutr 68(6):1157-1173

Carmichael CM, Mcgue M (1995) A cross-sectional examination of height, weight, and body-mass index in adult twins. J Gerontol A Biol Sci Med Sci 50(4):B237-B244

Cheung CYY, Tso AWK, Cheung BMY, Xu AM, Ong KL, Fong CHY, Wat NMS, Janus ED, Sham PC, Lam KSL (2010) Obesity susceptibility genetic variants identified from recent genomewide association studies: implications in a Chinese population. J Clin Endocrinol Metab 95(3):1395-1403

Donnelly JE, Blair SN, Jakicic JM, Manore MM, Rankin JW, Smith BK (2009) Appropriate physical activity intervention strategies for weight loss and prevention of weight regain for adults. Med Sci Sports Exerc 41(2):459-471

Dreon DM, Freyhewitt B, Ellsworth N, Williams PT, Terry RB, Wood PD (1988) Dietary-fat—carbohydrate ratio and obesity in middle-aged men. Am J Clin Nutr 47(6):995-1000

Funatogawa I, Funatogawa T, Nakao M, Karita K, Yano E (2009) Changes in body mass index by birth cohort in Japanese adults: results from the national nutrition survey of Japan 1956-2005. Int J Epidemiol 38(1):83-92

Genaro PD, Martini LA (2010) Effect of protein intake on bone and muscle mass in the elderly. Nutr Rev 68(10):616-623

Houston DK, Nicklas BJ, Ding JZ, Harris TB, Tylavsky FA, Newman AB, Lee JS, Sahyoun NR, Visser M, Kritchevsky SB, Study HA (2008) Dietary protein intake is associated with lean mass change in older, community-dwelling adults: the health, aging, and body composition (health $\mathrm{ABC}$ ) study. Am J Clin Nutr 87(1):150-155

Iannuzzi-Sucich M, Prestwood KM, Kenny AM (2002) Prevalence of sarcopenia and predictors of skeletal muscle mass in healthy, older men and women. J Gerontol A Biol Sci Med Sci 57(12):M772-M777

Kanehisa H, Fukunaga T (2013) Association between body mass index and muscularity in healthy older Japanese women and men. J Physiol Anthropol 32(1):4

Kim TN, Yang SJ, Yoo HJ, Lim KI, Kang HJ, Song W, Seo JA, Kim SG, Kim NH, Baik SH, Choi DS, Choi KM (2009) Prevalence of sarcopenia and sarcopenic obesity in Korean adults: the Korean sarcopenic obesity study. Int J Obes 33(8):885-892

Kobayashi S, Murakami K, Sasaki S, Okubo H, Hirota N, Notsu A, Fukui M, Date C (2011) Comparison of relative validity of food group intakes estimated by comprehensive and brief-type self-administered diet history questionnaires against $16 \mathrm{~d}$ dietary records in Japanese adults. Public Health Nutr 14(7): $1200-1211$

Kobayashi S, Honda S, Murakami K, Sasaki S, Okubo H, Hirota N, Notsu A, Fukui M, Date C (2012) Both comprehensive and brief self-administered diet history questionnaires satisfactorily rank nutrient intakes in Japanese adults. J Epidemiol 22(2):151-159

Korkeila M, Kaprio J, Rissanen A, Koskenvuo M (1991) Effects of gender and age on the heritability of body-mass index. Int J Obes 15(10):647-654

Kumahara H, Schutz Y, Ayabe M, Yoshioka M, Yoshitake Y, Shindo M, Ishii K, Tanaka H (2004) The use of uniaxial accelerometry for the assessment of physical-activity-related energy expenditure: a validation study against whole-body indirect calorimetry. Br J Nutr 91(2):235-243 
Levadoux E, Morio B, Montaurier C, Puissant V, Boirie Y, Fellmann N, Picard B, Rousset P, Beaufrere B, Ritz P (2001) Reduced whole-body fat oxidation in women and in the elderly. Int $\mathrm{J}$ Obes 25(1):39-44

Mozaffarian D, Hao T, Rimm EB, Willett WC, Hu FB (2011) Changes in diet and lifestyle and long-term weight gain in women and men. N Engl J Med 364(25):2392-2404

Murphy RA, Nalls MA, Keller M, Garcia M, Kritchevsky SB, Tylavsky FA, Newman AB, Tranah GJ, Eiriksdottir G, Gudnason V, Harris TB (2013) Candidate gene association study of BMI-associated loci, weight, and adiposity in old age. J Gerontol A Biol Sci Med Sci 68(6):661-666

Ochi M, Tabara Y, Kido T, Uetani E, Ochi N, Igase M, Miki T, Kohara K (2010) Quadriceps sarcopenia and visceral obesity are risk factors for postural instability in the middle-aged to elderly population. Geriatr Gerontol Int 10(3):233-243

Oken E, Gillman MW (2003) Fetal origins of obesity. Obes Res 11(4):496-506

Peterson RE, Maes HH, Holmans P, Sanders AR, Levinson DF, Shi JX, Kendler KS, Gejman PV, Webb BT (2011) Genetic risk sum score comprised of common polygenic variation is associated with body mass index. Hum Genet 129(2):221-230

Popkin BM, Doak CM (1998) The obesity epidemic is a worldwide phenomenon. Nutr Rev 56(4):106-114

Renstrom F, Payne F, Nordstrom A, Brito EC, Rolandsson O, Hallmans G, Barroso I, Nordstrom P, Franks PW (2009) Replication and extension of genome-wide association study results for obesity in 4923 adults from northern Sweden. Hum Mol Genet 18(8):1489-1496

Rising R, Tataranni PA, Snitker S, Ravussin E (1996) Decreased ratio of fat to carbohydrate oxidation with increasing age in Pima Indians. J Am Coll Nutr 15(3):309-312

Sasaki S, Katagiri A, Tsuji T, Shimoda T, Amano K (2003) Selfreported rate of eating correlates with body mass index in 18-yold Japanese women. Int J Obes 27(11):1405-1410

Song MY, Ruts E, Kim J, Janumala I, Heymsfield S, Gallagher D (2004) Sarcopenia and increased adipose tissue infiltration of muscle in elderly African American women. Am J Clin Nutr 79(5):874-880

Stookey JD (2001) Energy density, energy intake and weight status in a large free-living sample of Chinese adults: exploring the underlying roles of fat, protein, carbohydrate, fiber and water intakes. Eur J Clin Nutr 55(5):349-359

Tanisawa K, Ito T, Sun X, Cao ZB, Sakamoto S, Tanaka M, Higuchi M (2014) Polygenic risk for hypertriglyceridemia is attenuated in Japanese men with high fitness levels. Physiol Genomics 46(6):207-215

Thorleifsson G, Walters GB, Gudbjartsson DF, Steinthorsdottir V, Sulem P, Helgadottir A, Styrkarsdottir U, Gretarsdottir S, Thorlacius S, Jonsdottir I, Jonsdottir T, Olafsdottir EJ, Olafsdottir GH, Jonsson T, Jonsson F, Borch-Johnsen K, Hansen T, Andersen G, Jorgensen T, Lauritzen T, Aben KK, Verbeek ALM, Roeleveld N, Kampman E, Yanek LR, Becker LC, Tryggvadottir L, Rafnar T, Becker DM, Gulcher J, Kiemeney LA, Pedersen O, Kong A, Thorsteinsdottir U, Stefansson K (2009) Genome-wide association yields new sequence variants at seven loci that associate with measures of obesity. Nat Genet 41(1):18-24

Tremblay A, Simoneau JA, Bouchard C (1994) Impact of exercise intensity on body fatness and skeletal-muscle metabolism. Metabolism 43(7):814-818

Treuth MS, Hunter GR, Weinsier RL, Kell SH (1995) Energyexpenditure and substrate utilization in older women after strength training-24-H calorimeter results. J Appl Physiol 78(6):2140-2146

Treuth MS, Hunter GR, Williams M (1996) Effects of exercise intensity on 24-h energy expenditure and substrate oxidation. Med Sci Sports Exerc 28(9):1138-1143

Usui C, Asaka M, Kawano H, Aoyama T, Ishijima T, Sakamoto S, Higuchi M (2010) Visceral fat is a strong predictor of insulin resistance regardless of cardiorespiratory fitness in non-diabetic people. J Nutr Sci Vitaminol 56(2):109-116

Wen WQ, Cho YS, Zheng W, Dorajoo R, Kato N, Qi L, Chen CH, Delahanty RJ, Okada Y, Tabara Y, Gu DF, Zhu DL, Haiman CA, Mo ZN, Gao YT, Saw SM, Go MJ, Takeuchi F, Chang LC, Kokubo Y, Liang J, Hao M, Le Marchand L, Zhang Y, Hu YL, Wong TY, Long JR, Han BG, Kubo M, Yamamoto K, Su MH, Miki T, Henderson BE, Song HD, Tan AH, He J, Ng DPK, Cai QY, Tsunoda T, Tsai FJ, Iwai N, Chen GK, Shi JJ, Xu JF, Sim XL, Xiang YB, Maeda S, Ong RTH, Li C, Nakamura Y, Aung T, Kamatani N, Liu JJ, Lu W, Yokota M, Seielstad M, Fann CSJ, Wu JY, Lee JY, Hu FB, Tanaka T, Tai ES, Shu XO, Tria GIA (2012) Meta-analysis identifies common variants associated with body mass index in east Asians. Nat Genet 44(3):307-311

WHO Expert Consultation (2004) Appropriate body-mass index for Asian populations and its implications for policy and intervention strategies. Lancet 363(9403):157-163

Willer CJ, Speliotes EK, Loos RJF, Li SX, Lindgren CM, Heid IM, Berndt SI, Elliott AL, Jackson AU, Lamina C, Lettre G, Lim N, Lyon HN, McCarroll SA, Papadakis K, Qi L, Randall JC, Roccasecca RM, Sanna S, Scheet P, Weedon MN, Wheeler E, Zhao JH, Jacobs LC, Prokopenko I, Soranzo N, Tanaka T, Timpson NJ, Almgren P, Bennett A, Bergman RN, Bingham SA, Bonnycastle LL, Brown M, Burtt NLP, Chines P, Coin L, Collins FS, Connell JM, Cooper C, Smith GD, Dennison EM, Deodhar P, Elliott P, Erdos MR, Estrada K, Evans DM, Gianniny L, Gieger C, Gillson CJ, Guiducci C, Hackett R, Hadley D, Hall AS, Havulinna AS, Hebebrand J, Hofman A, Isomaa B, Jacobs KB, Johnson T, Jousilahti P, Jovanovic Z, Khaw KT, Kraft P, Kuokkanen M, Kuusisto J, Laitinen J, Lakatta EG, Luan J, Luben RN, Mangino M, McArdle WL, Meitinger T, Mulas A, Munroe PB, Narisu N, Ness AR, Northstone K, O'Rahilly S, Purmann C, Rees MG, Ridderstraale M, Ring SM, Rivadeneira F, Ruokonen A, Sandhu MS, Saramies J, Scott LJ, Scuteri A, Silander K, Sims MA, Song K, Stephens J, Stevens S, Stringham HM, Tung YCL, Valle TT, Van Duijn CM, Vimaleswaran KS, Vollenweider P, Waeber G, Wallace C, Watanabe RM, Waterworth DM, Watkins N, Witteman JCM, Zeggini E, Zhai GJ, Zillikens MC, Altshuler D, Caulfield MJ, Chanock SJ, Farooqi IS, Ferrucci L, Guralnik JM, Hattersley AT, Hu FB, Jarvelin MR, Laakso M, Mooser V, Ong KK, Ouwehand WH, Salomaa V, Samani NJ, Spector TD, Tuomi T, Tuomilehto J, Uda M, Uitterlinden AG, Wareham NJ, Deloukas P, Frayling TM, Groop LC, Hayes RB, Hunter DJ, Mohlke KL, Peltonen L, Schlessinger D, Strachan DP, Wichmann HE, McCarthy MI, Boehnke M, Barroso I, Abecasis GR, Hirschhorn JN, Control WTC, Consortium G (2009) Six new loci associated with body mass index highlight a neuronal influence on body weight regulation. Nat Genet 41(1):25-34

Yamada M, Moriguch Y, Mitani T, Aoyama T, Arai H (2014) Agedependent changes in skeletal muscle mass and visceral fat area in Japanese adults from 40 to 79 years-of-age. Geriatr Gerontol Int 14:8-14

Zamboni M, Zoico E, Scartezzini T, Mazzali G, Tosoni P, Zivelonghi A, Gallagher D, De Pergola G, Di Francesco V, Bosello O (2003) Body composition changes in stable-weight elderly subjects: the effect of sex. Aging Clin Exp Res 15(4):321-327 